\title{
Procedimentos e percepções sobre a orientação na EAD: o caso da especialização em mídias na educação
}

\author{
Sílvia Porto Meirelles Leite ${ }^{1}$ \\ Walter Ruben Iriondo Otero ${ }^{1}$ \\ ${ }^{1}$ Centro de Educação a Distância - Universidade Federal de Pelotas (UFPEL) \\ silviameirelles@gmail.com,wiriondo@gmail.com
}

Resumo: O presente trabalho apresenta a implementação do processo de orientação na Especialização em Mídias na Educação da Universidade Federal de Pelotas (UFPel). Essa primeira análise tem o objetivo de trazer subsídios para a elaboração de uma metodologia que indique caminhos para o processo de orientação de trabalho de conclusão de curso ofertada na modalidade a distância. Para tanto, são detalhados os procedimentos adotados na experiência analisada, bem como a percepção dos professores sobre o processo proposto pelo curso. Contribui para a análise o levantamento realizado junto aos orientadores do curso, o qual foi feito através de um formulário que deveria ser preenchido via Internet. A partir disso, estão sendo propostos ajustes concernentes às demandas identificadas.

Palavras-chave: orientação; pós-graduação; educação a distância.

\section{Procedures and perceptions about the orientation in distance education: the case of postgraduate courses in media education}

\begin{abstract}
This paper presents the implementation of process orientation in postgraduate courses in Media Education, Federal University of Pelotas (UFPel). This first analysis aims to provide support for the development of a methodology to indicate paths for the orientation process for completion of course work offered in distance mode. Therefore, the procedures adopted are detailed analyzed in the experiment, as well as the teachers' perception of the process proposed by the course. Analysis contributes to the survey carried out among guiding the course, which was done through a form that should be completed via the Internet. From this, adjustments are being proposed reading the demands identified.
\end{abstract}

Keywords: orientation; postgraduate courses; distance education

\section{Introdução}

O presente artigo aborda a implementação do processo de orientação dos trabalhos finais de cursos de Pós-Graduação ofertados na modalidade Educação a Distância (EAD). Para tanto, traz uma leitura das especificidades da pós-graduação na EAD, bem como da configuração do processo de orientação e da relação orientador/orientando nessa modalidade de ensino. A partir disso, apresenta-se o trabalho realizado com orientadores dos artigos finais de alunos do curso de Especialização em Mídias na Educação da Universidade Federal de Pelotas (UFPEL), a fim de propor uma reflexão sobre a orientação de trabalhos finais na EAD.

Tal abordagem justifica-se pela expansão dos cursos de Pós-Graduação na EAD ofertados por instituições públicas e privadas. Atualmente, a Universidade Aberta do Brasil 
(UAB) tem cadastrado no SISUAB $^{1}$ a oferta de 310 cursos de Especialização. Além dos cursos de Pós-Graduação Lato Sensu, também existe, no âmbito da UAB, um Mestrado Profissional em Matemática (Pofmat), e estão sendo analisadas as propostas de cursos de Mestrado nas áreas de Letras, Química e Física (TEATINI, 2012).

Dentre os inúmeros desafios enfrentados pela Pós-graduação na EAD, esse artigo evidencia a implementação de um processo de orientação que garanta: aporte técnico para os orientadores acompanharem seus alunos e realizarem intervenções, bem como a gestão das informações concernentes à orientação por parte da coordenação do curso. A fim de refletir sobre as possibilidades da implementação do processo de orientação, serão detalhadas as estratégias adotadas no curso de Mídias na Educação/UFPEL, bem como um levantamento realizado com os orientadores desse curso sobre a estrutura de trabalho adotada.

\section{Pós-Graduação e EAD}

De acordo com a legislação brasileira (Brasil 2005), a Educação a Distância é caracterizada como uma modalidade educacional, na qual estudantes e professores desenvolvem atividades educativas com o suporte de Tecnologias da Informação (TICs) em lugares ou tempos diversos. A trajetória da EAD no Brasil passou por diferentes processos e utilizou diferentes meios e tecnologias, tais como: correspondência de material impresso, recursos audiovisuais (televisão, rádio e fitas de vídeo), suporte on-line da Internet e Mobile Learning (celulares e comunicação de rede sem fio). Com a expansão da comunicação via Internet e com a convergência das mídias, ampliaram-se as possibilidades de interação entre as pessoas e o acesso a conteúdos digitais, potencializando a mediação didático-pedagógica a distância.

Se por um lado tem-se o engendramento de novos espaços de atuação na EAD, de outro, configura-se a necessidade de refletir os processos de formação e orientação na modalidade a distância, buscando atender suas especificidades. Essa questão pode ser destacada no caso dos cursos de Pós-Graduação, os quais agregam a elaboração de um trabalho de conclusão e a construção da relação orientador/orientando.

De acordo com Almeida (2012), os cursos de pós-graduação na EAD devem preservar "princípios da interação, colaboração, investigação, reflexão e construção do conhecimento, essenciais em qualquer modalidade educativa” (p.1058). A EAD possibilita a formação de profissionais que estão exercendo o seu ofício, de modo que eles não precisam se afastar das suas atividades profissionais para dar continuidade aos seus estudos. Com isso, fomenta-se o trabalho da própria prática profissional como objeto de estudo. A autora aponta um conjunto de referências para a elaboração de propostas de cursos de pós-graduação stricto sensu na modalidade a distância, com ênfase para o desenvolvimento de método científico com rigor metodológico e para a construção de projetos que integrem espaços presenciais e virtuais. Esse processo comporta à integração das TICs ao currículo e à pesquisa científica.

Nessa abordagem, pode-se observar uma estreita relação entre a pesquisa científica, o espaço de trabalho e o ambiente de aprendizagem. Esses princípios possibilitam a articulação entre atividades profissionais e uma construção teórico-metodológica consistente. Assim, o investimento em pós-graduação na modalidade a distância, stricto ou lato sensu, corroboram para uma qualificação das atividades profissionais, principalmente no que se refere à formação de professores.

1 SISUAB é o sistema utilizado para a gestão das informações sobre cursos e Polos UAB, sendo possível consultar a oferta e dados administrativos dos cursos. Está disponível em:

http://sisuab.capes.gov.br/ 
Os cursos de pós-graduação ofertados no Brasil na EAD geralmente envolvem professores, tutores e alunos; atores que interagem no decorrer das disciplinas curriculares. Entretanto, concluídas as disciplinas, tem-se o momento de elaboração do trabalho de conclusão de curso, etapa em que se tem uma reconfiguração das funções. Durante as disciplinas, existe o professor que responde pelo conteúdo, pela proposição de atividades e pela gestão das aprendizagens; atividades realizadas com o suporte dos tutores, que são responsáveis por auxiliar os alunos nos procedimentos solicitados pelo professor. Chegada a etapa da orientação, surge a figura do professor orientador, que está mais próximo de um grupo reduzido de alunos e realiza intervenções mais pontuais com seus orientandos. Essa transição para a etapa de elaboração de um trabalho de conclusão é um momento delicado para a gestão das informações e das atividades do curso. Pois a coordenação do curso passa a trabalhar com um grande número de professores envolvidos nas orientações, o que exige um esforço adicional no acompanhamento do trabalho. Nessa etapa o desafio consiste em estabelecer estratégias que contribuam para a sistematização do processo de orientação e que possibilitem o acompanhamento do processo por parte da coordenação do curso. Não cabe à coordenação do curso interferir na relação entre orientador e orientando, mas é preciso estabelecer regras que balizem o trabalho e que ofereçam subsídios, tanto para o orientador como para seus orientandos.

Dentre as particularidades do processo de orientação, destaca-se a necessidade de interações que contribuem para a construção de conhecimento. Schnitman (2011) aponta para a figura do Professor Mediador, responsável pela mediação da interação entre os alunos e pela promoção da interatividade em Ambientes Virtuais de Aprendizagem (AVA). Ao analisar a interação pedagógica de professores orientadores na disciplina de Orientação de Trabalho de Conclusão de Curso, Schnitman questiona a educação de massa e procura investir na mediação como princípio pedagógico básico. De acordo com a autora, é preciso atentar para o grau de interação mantido pelo orientador para compreender o resultado final do trabalho. A partir da pesquisa realizada com 403 alunos da etapa de elaboração do trabalho de conclusão de dezesseis cursos de especialização ofertados na modalidade a distância, Schnitman observou que quanto maior o grau de interação do orientador com seus alunos, mais chances do trabalho ser indicado para a defesa. Nessa pesquisa, dos 403 alunos que iniciaram o trabalho de conclusão, somente 190 foram recomendados para a defesa por seus orientadores. Tendo como base uma análise quantitativa das interações entre orientador e orientando e do número de recomendações para defesa, Schnitman destaca que "a condução da mediação, por parte dos orientadores, é estatisticamente significante para a recomendação ou não recomendação do TCC para a defesa” (p. 312).

Brunetta (2012), a partir de uma pesquisa com estudantes de EAD de graduação e pós-graduação sobre a elaboração do trabalho de final de curso destaca como aspectos importantes para a construção do trabalho: “[...]administração do tempo; dificuldade de acesso ao campo de pesquisa e de acesso a materiais bibliográficos; dificuldade para redigir um texto no modelo de redação científica e problemas pessoais” (pág. 5). De acordo com os depoimentos dos alunos, esses aspetos envolvem a dificuldade de conciliar atividades profissionais e acadêmicas, os trâmites burocráticos (como a autorização de ingresso ao contexto da pesquisa) e questões de cunho pessoal. Também foi mencionado o nível de dificuldade da escrita científica.

Ao questionar os tutores sobre a sua função na elaboração do trabalho final de curso, Brunetta observou que eles destacam a sua função de motivador, tendo em vista que a escrita do trabalho é uma tarefa solitária. Também foi elucidado o suporte aos aspectos técnicos e didáticos, bem como a presença constante junto ao aluno. Sobre as dificuldades encontradas 
pelos alunos, os tutores mencionaram a falta de acesso a materiais e fontes de pesquisa e a redação de um trabalho científico. Eles também apontaram a necessidade de uma aproximação entre orientadores e tutores, a fim de construir uma linha comum de orientação. $\mathrm{Na}$ opinião dos professores orientadores, o tutor tem um papel fundamental no processo de orientação, pois ele ajuda a delimitar o trabalho e estimula o aluno a se tornar um sujeito crítico, em muitos casos é ele que articula o diálogo entre orientador e aluno. Sobre os alunos, os orientadores mencionaram a importância do desenvolvimento da autonomia do aluno, da criação de uma rotina de estudos e de administrar o seu tempo de dedicação ao trabalho final.

A partir das questões apontadas sobre a pós-graduação ofertada na EAD, entende-se que a construção da pesquisa e o processo de orientação deve priorizar: o uso de tecnologias que promovam a interação e a colaboração, o fomento à investigação e à reflexão, a articulação entre as atividades profissionais e a pesquisa de conclusão de curso, a condução da mediação por parte dos orientadores, a promoção de encontros entre professor orientador e alunos, o estabelecimento de rotinas de estudo e escrita, a acesso à materiais bibliográfico e a constante motivação para que os alunos não se sintam abandonados. Esses aspectos podem orientar a sistemática de trabalho proposta pelo curso, a fim de promover um contexto de pesquisa e construção de conhecimento.

\section{Pós-Graduação em Mídias na Educação na UFPel}

A pós-graduação em Mídias na Educação tem como objetivo principal investir na formação de professores de Educação Básica, criando condições para que esses professores possam estudar as questões relacionadas ao uso pedagógico das mídias no seu contexto profissional. O programa Mídias na Educação vem trabalhando com essa proposta desde 2006, inicialmente era desenvolvido pela Secretaria de Educação a Distância (Seed) do Ministério de Educação (MEC), em parceria com secretarias de educação e universidades públicas. Em 2010, os cursos passaram a ser ofertados e financiados pela UAB e disponibilizados nos polos de Apoio Presencial cadastrados pela UAB. As universidades públicas são responsáveis pela oferta e certificação dos módulos e pela seleção e capacitação de tutores.

O programa Mídias na Educação do Governo Federal contempla cursos de extensão, aperfeiçoamento e especialização. Conforme consulta ao SISUAB, atualmente a UAB tem cadastrados 53 cursos ativos no Brasil do programa, sendo que 35 cursos são de Especialização. A UFPEL é uma das instituições indicadas pelo SISUAB que oferta a Especialização em Mídias na Educação. O objetivo do curso é contribuir para a formação de profissionais em educação, em especial professores da Educação Básica, capazes de produzir e estimular estratégias didáticas com diferentes mídias, articulando linguagens de comunicação com os processos de ensino e aprendizagem.

O curso é ofertado na modalidade a distância e atende seis polos de apoio presencial UAB, com um total de 282 alunos matriculados. Atualmente, o curso está na etapa de elaboração do trabalho de conclusão, que consiste em realizar uma pesquisa na área das Mídias na Educação e apresentar os resultados no formato de um artigo científico. Foram encaminhados para essa etapa 154 alunos, os quais estão sob a supervisão de professores orientadores. Dentre os motivos para o aluno não ser encaminhado à etapa de escrita do artigo final estão: desligamento oficial do curso, problemas de saúde, abandono de curso e reprovação em uma ou mais disciplinas.

A fim de atender a demanda desses 154 alunos, foram integrados 29 orientadores ao corpo docente do curso. Nem todos os orientadores tinham experiência com a e EAD, de 
modo que foi proposta uma formação sobre as atribuições do orientador na EAD e ferramentas que poderiam auxiliar na interação com os alunos. Dentre os recursos indicados para a comunicação entre orientador e orientando, estão: o Moodle (para a troca de arquivos e interação assíncrona) e Skype e GoogleTalk (para comunicação síncrona). Para tanto, foi criado no Moodle do curso o espaço Sala de Orientadores, numa alusão à Sala dos Professores. Nesse espaço, foram disponibilizados: as atribuições dos orientadores; tutorial com as normas para a elaboração do artigo de conclusão de curso e tutoriais sobre os editores de texto com os recursos para formatação. Também se disponibilizou subsídios sobre a identificação de plágio na escrita dos alunos, bem como sistemas que auxiliam na identificação de textos copiados da Internet. Os orientadores responderam um questionário, no qual apontaram: quantos alunos gostariam de orientar, áreas do conhecimento e mídias que gostariam de trabalhar e os polos que gostariam de atender.

Dentro da proposta de orientação elaborada pelo curso, foram definidas as figuras do orientador e coorientador. Os orientadores atendem entre dois e dez alunos, atuam nas áreas de educação e/ou mídias e tem, no mínimo, Mestrado. A equipe de coorientadores é composta pelos tutores do curso, os quais acompanharam os alunos durante as disciplinas, eles são especialistas, de modo que já passaram pelo processo de construção do trabalho final de uma especialização. Dentre as atribuições do orientador, destaca-se: realização de pelo menos quatro encontros síncronos com os alunos; orientação quanto ao planejamento do trabalho e rigor teórico e metodológico; sugestão de leituras e verificação da existência de plágio. Dentre as funções do coorientador, destaca-se orientar sobre: as normas de formação e estrutura do trabalho, a utilização dos editores de texto e o cumprimento dos prazos estipulados no cronograma do curso. O coorientador não tem a função de formatar o trabalho dos alunos, mas de ensinar como fazer, de modo que a organização das informações integra a formação do aluno.

Também se criou um espaço denominado "Sala de Integração/Orientação", o qual foi destinado às trocas entre orientadores, alunos e coorientadores. Nesse espaço, o curso disponibilizou para alunos e professores: cronograma de trabalho, uma biblioteca de links para artigos e revistas científicas e tutoriais de editores de texto formatação de artigos científicos. Com isso, buscou-se instrumentalizar orientadores, tutores e alunos com os recursos pertinentes para o processo de orientação. Nessa sala foram criados fóruns de orientadores e, em cada fórum, foi criado um tópico para cada orientando, nos quais podem ocorrer trocas de arquivos e interações assíncronas, o que possibilita um mapeamento de mensagens e arquivos enviados durante a orientação.

Os orientadores também tem acesso a um espaço no Google Drive, destinado ao diário de orientação. Cada orientador tem acesso ao seu diário e a coordenação do curso tem acesso a todos os diários. O objetivo desse espaço é ter o registro dos encaminhamentos dos encontros síncronos, bem como do avanço do processo de orientação. Essas estratégias e os materiais utilizados foram elaborados por uma equipe do curso, que debateu e formulou as etapas de um processo de orientação a distância. A proposta da sistematização desses procedimentos para o processo de orientação é assegurar que alunos, coorientadores e orientadores tenham a assistência da coordenação e da equipe de suporte no decorrer da orientação. Com isso é possível ter acesso às informações que vão subsidiar as decisões no caso de um contratempo.

\section{A Coleta de Dados realizada com os Orientadores}


Com o objetivo de refletir sobre o processo de orientação dos trabalhos finais do curso de Mídias na Educação, buscou-se analisar os procedimentos adotados e as percepções dos professores orientadores. Essa análise subsidiará as correções no processo proposto inicialmente, visando estabelecer etapas para o gerenciamento das orientações na EAD.

A fim de analisar como os Professores Orientadores se apropriaram dos procedimentos descritos, a Coordenação do Curso realizou um levantamento via questionário eletrônico. Para tanto, os Orientadores foram convidados a responder questões sobre: o grau de facilidade/dificuldade em desempenhar as atribuições como orientador; a realização dos encontros síncronos; o auxílio na resolução de problemas conceituais e técnicos; o cumprimento das normas estipuladas no tutorial de elaboração do artigo; o trabalho em parceria com o Tutor Coorientador e o grau de utilização das ferramentas disponibilizadas. Solicitou-se que indicassem outros recursos utilizados na orientação.

O questionário foi aplicado na última semana do mês de março de 2013, durante o processo de orientação, e foi respondido por 19 Orientadores do curso. Algumas das questões objetivas procuraram identificar o grau de facilidade/dificuldade do professor na execução de suas atribuições como orientador do curso de Mídias na Educação. Para tanto foi utilizada uma escala de Likert, na qual o respondente devia apontar, para cada uma das referidas atribuições, um valor indicando o grau de facilidade/dificuldade na execução das referidas atribuições. A escala foi organizada na seguinte estrutura: 1-Muito Difícil; 2Difícil; 3-Nem fácil nem difícil; 4-Fácil e 5-Muito Fácil.

Outras questões procuraram identificar o grau de utilidade dos recursos disponibilizados para as tarefas de orientação; de modo que o respondente devia apontar um valor que indicasse o grau de utilidade de cada um dos recursos apontados no questionário. A escala foi organizada na seguinte estrutura: 1-Sem utilidade; 2-Pouca utilidade; 3-Sem opinião formada; 4-Útil e 5-Muito útil.

Na análise dos resultados, a pontuação obtida em cada questão objetiva foi totalizada para se obter um valor que represente, em média, a opinião de todos os respondentes. As questões dissertativas possibilitaram aos Orientadores expressar comentários em relação à orientação de alunos do curso de Mídias na Educação; comentários em relação a outros recursos utilizados na orientação dos alunos (além daqueles oferecidos pela Coordenação do Curso); e comentários gerais.

\section{Resultados da Aplicação do Questionário}

A partir das respostas dos orientadores, pode-se observar que a maioria deles mostrou-se satisfeitos com a metodologia proposta para as orientações. Essa questão pode ser observada em trechos dos registros feitos pelos orientadores ao responder o questionário, os quais são apresentados a seguir.

R11 - “[...] achei o curso extremamente organizado”

R4 - "[...] estou muito bem impressionada com a estrutura de suporte que o curso criou para a construção dos trabalhos, pois colabora com o trabalho do orientador”.

R3 - "O curso como um todo foi muito bem organizado e com um bom grau de exigência dos alunos, o qual acredito que contribuiu para a formação desses profissionais. Em relação ao processo de orientação, esse foi bem organizado, no entanto alguns alunos se esquivaram e não aproveitaram os meses de janeiro e fevereiro para trabalhar no artigo.” 
Os orientadores foram questionados em relação ao grau de dificuldade/facilidade referente a suas atribuições. O Quadro 1 apresenta as atribuições que foram apontadas com maior grau de dificuldade.

\begin{tabular}{|l|l|}
\hline Atribuição do Orientador & Opinião \\
\hline $\begin{array}{l}\text { Cumprir e cobrar do aluno o cumprimento dos prazos estipulados no cronograma de } \\
\text { elaboração do Trabalho de Conclusão }\end{array}$ & 2,63 \\
\hline Aprovar o pré-projeto dos seus orientandos em dezembro de 2012 & 2,89 \\
\hline Verificar a possibilidade de existência de Plágio & 2,89 \\
\hline Trabalhar em parceria com o Tutor Coorientador & \\
\hline
\end{tabular}

Quadro 1. Atribuições apontadas como de maior grau de dificuldade.

A respeito das dificuldades enfrentadas pelos orientadores, principalmente no que concerne ao cumprimento dos prazos e administração do tempo por parte dos alunos, a seguir são evidenciados alguns comentários postados pelos orientadores.

R3 - "A maior dificuldade no processo de orientação, em minha opinião, incidiu no fato de alguns alunos "sumirem", não me darem retorno, nem e-mail, nem mensagem, nem resposta no facebook e nem atendiam ou não falavam com a tutora presencial do Polo, quando ela ligava. [...] Assim por uma questão de tempo, alguns trabalhos perderão em qualidade principalmente em aprofundamento teórico e discussão dos resultados.”

R10 - "Penso que deveria haver mais rigidez quanto aos cumprimentos de prazos. [...] eu tenho cumprido com os prazos, mas os alunos não parecem muito fiéis aos prazos estipulados e dos 4 orientandos que me propus a orientar apenas duas continuam e com muita cobrança minha.”

R4 - "[...] a disponibilidade dos estudantes para fazer o trabalho tem sido o maior empecilho que encontrei até agora, já que pouco têm assumido a tarefa da maneira necessária. [...] o baixo grau de interação (tanto nas respostas às mensagens postadas no fórum quando na disponibilidade em comparecer nos encontros síncronos) de alguns estudantes se reflete na baixa evolução do trabalho.”

A dificuldade na administração do tempo para a escrita do trabalho de conclusão de curso também foi apontado por Brunetta (2012) como um dos aspectos observados nesse processo. De acordo com a autora, orientadores e tutores mencionaram essa falta de organização dos alunos para disciplinar a construção do trabalho de final. Por outro lado, os alunos mencionaram a dificuldade em conciliar atividades profissionais e acadêmicas e demandas pessoais. Assim, identifica-se a necessidade de se elaborar procedimentos que auxiliem o aluno a administrar o seu tempo para atender as demandas desse processo de escrita. Elucida-se o caráter pedagógico de se investir, desde o início das disciplinas curriculares, na prática de estabelecer rotinas de trabalho para as atividades de cursos EAD.

Além da questão da administração temporal, também se observou em alguns relatos uma diferença de calendário entre as atividades do curso e as atividades na sua instituição de atuação profissional. Os alunos da especialização realizaram os trabalhos das disciplinas com as suas turmas em 2012, mas começaram a escrever o artigo final no início de 2013, quando já tinham trocado de turma e/ou de escola e estavam trabalhando com novos sujeitos. Em algumas situações, essa diferença pode ter interferido na relação entre a prática docente e a pesquisa desenvolvida no artigo final, bem como na configuração da própria prática profissional como objeto de estudo.

R14. [...]Tenho duas alunas que agora, no início do ano, estão colocando em prática (usando como procedimento técnico a pesquisa-ação) o uso da mídia usada na pesquisa, no caso o blog, pois até 
então tudo indicava que já estavam utilizando a ferramenta. Então elas precisam ao mesmo tempo que constroem o artigo, realizar a prática.

R13. - [...] Outra questão foi o desencontro do calendário de orientação com o calendário escolar. Como elas pesquisam sobre sua prática somente conseguiram executar os projetos escolares em março, ficando reduzido o tempo para análise e escrita do artigo. Elas apresentaram muita dificuldade em diferenciar o projeto escolar do projeto de pesquisa. Pensavam q era só aplicar tal ação pedagógica e relatar.

Além das questões apontadas acima, o respondente R8 disse ter encontrado alunos motivados com o curso, alguns com dificuldade no conhecimento de um trabalho acadêmico, mas sendo isso algo comum no processo de orientação.

O Quadro 2 apresenta as atribuições que ofereceram maior grau de facilidade, segundo os respondentes do questionário.

\begin{tabular}{|l|l|}
\hline Atribuição do Orientador & Opinião \\
\hline Realizar pelo menos quatro encontros síncronos (entre dez/2012 e abr/2013) & 3,05 \\
\hline Auxiliar o aluno na resolução de problemas conceituais e técnicos & 3,21 \\
\hline Manter atualizado o Formulário de Orientação disponibilizado no GoogleDocs & 3,26 \\
\hline $\begin{array}{l}\text { Orientar quanto à leitura e cumprimento das normas estipuladas no tutorial de elaboração } \\
\text { do artigo }\end{array}$ & 3,32 \\
\hline Orientar quanto à elaboração do planejamento do trabalho & 3,58 \\
\hline Sugerir leituras e autores pertinentes ao tema do trabalho & 3,63 \\
\hline
\end{tabular}

Quadro 2. Atribuições apontadas como de menor grau de dificuldade.

Vale destacar que a atribuição de "Orientar a elaboração do trabalho com rigor teórico e metodológico” recebeu, em média, o grau 3,00, de acordo com o método quantitativo adotado o grau 3 representa a opinião neutra “Nem fácil nem difícil”. De acordo com Almeida (2012) e Schnitman (2011) o rigor teórico-metodológico é um dos desafios para a consolidação da pós-graduação a distância, o que envolve a formação dos profissionais envolvidos em cursos EAD e um investimento na condução da mediação por parte do professor/orientador. Entende-se que esse processo inicia com as disciplinas curriculares, mas ele ganha maior visibilidade com a escrita do trabalho final, quando os alunos precisam olhar para a prática docente como um objeto de pesquisa e sistematizar isso através da escrita acadêmica.

Os orientadores foram questionados a respeito do grau de utilidade dos recursos oferecidos para o desenvolvimento das tarefas relativas à orientação dos alunos. Todos os recursos apresentaram algum grau de utilidade, conforme observado no Quadro 3.

\begin{tabular}{|l|l|}
\hline Suporte disponibilizado aos Orientadores & Opinião \\
\hline $\begin{array}{l}\text { Tutoriais para realizar web conferências (utilizando Skype, Google Talk, e plataforma } \\
\text { RNP) }\end{array}$ & 3,95 \\
\hline Repositório no AVA para inserir artigos para seus orientandos & 4,11 \\
\hline Fórum de Orientações no AVA para dialogar com os orientandos & 4,16 \\
\hline $\begin{array}{l}\text { Reuniões da Coordenação do Curso com os Orientadores para explicar metodologia de } \\
\text { trabalho }\end{array}$ & 4,37 \\
\hline Tutorial para elaboração do artigo & 4,84 \\
\hline Modelo do artigo (Word e Writer) & 4,89 \\
\hline
\end{tabular}

Quadro 3. Grau de utilidade dos recursos oferecidos pela coordenação do curso 
A respeito da utilidade de recursos que possibilitam a realização de reuniões síncronas com seus orientandos, o registro das opiniões está no Quadro 4.

\begin{tabular}{|l|l|}
\hline Recursos sugeridos para reuniões com os orientandos & Opinião \\
\hline Sala de web conferências da RNP para comunicar-se com os orientandos & 2,84 \\
\hline Hangout do Google+ para comunicar-se com os orientandos & 3,21 \\
\hline Google Talk para comunicar-se com os orientandos & 3,42 \\
\hline Skype para comunicar-se com os orientandos & 4,37 \\
\hline
\end{tabular}

Quadro 4. Grau de utilidade dos recursos oferecidos para as reuniões síncronas

Pode-se observar que a utilização da sala de web conferências oferecida aos cursos da UAB pela Rede Nacional de Ensino e Pesquisa (RNP) foi o recurso considerado com menor utilidade pelos professores orientadores. Este fato poderia ser interpretado como eventual desconhecimento das facilidades oferecidas pela referida ferramenta. Além disso, o seu uso depende de agendamento com o setor responsável pela administração do sistema na UFPEL, de modo que o orientador não pode acessá-lo a qualquer momento com sua própria senha.

No que se refere à metodologia adotada nas orientações e quanto à utilização de outros recursos na orientação, os mais citados foram o Facebook e o e-mail. A esse respeito, evidenciam-se os comentários apresentados a seguir.

R4 - "Costumo trocar arquivos e "fazer combinações" basicamente pela plataforma; nas circunstâncias em que a plataforma falha (no caso de recusar anexos maiores, por exemplo), uso email. As orientações em si são feitas através de sugestões no corpo do trabalho e via Skype, quando são necessárias diretrizes "maiores"/mais relevantes; destaco."

R3 - "O processo de orientação foi conduzido por e-mail, visto que o fórum disponibilizado na sala de orientação era de visualização de todos. Deste modo, para não ocorrer problemas de cópias dos trabalhos dos alunos os arquivos foram anexados em e-mails. O skype e o facebook foram as duas formas utilizadas para os encontros. Deixei a cargo de cada orientada a escolha da forma em que se sentia mais segura para nos comunicarmos. A maioria optou pelo facebook, mas algumas foram realizadas pelo skype."

R10 - "O que mais utilizo é o facebook. Até para dar umas "sacudidas" para me responderem as mensagens quando vejo que estão conectados”.

Destaca-se a importância de incentivar os momentos de interação entre orientador e aluno, tanto síncronos quanto assíncronos, o que colabora para o enriquecimento da mediação e para a constante motivação para que os alunos não se sintam abandonados. A opção de se investir no Moodle como um espaço de interação assíncrona, teve como premissa o seu caráter institucional, servindo de referência para identificar possíveis carências no processo de orientação. No que se refere à sistemática proposta de encontros síncronos, buscou-se formas de se fomentar as trocas entre os envolvidos no processo de orientação. Além das propostas apresentadas pela coordenação do curso, também foram apontadas outros caminhos, como o próprio Facebook, o que será considerado pela coordenação do curso nas próximas edições.

\section{Conclusões}


Essa análise inicial sobre os procedimentos adotados no processo de orientação da Especialização em Mídias na Educação/UFPEL contribuiu para se identificar a evasão dos alunos durante as disciplinas e na escrita do trabalho final. A Coordenação do Curso está refletindo e procurando respostas que justifiquem a evasão, bem como a implementação de estratégias para minimizá-la. Nesse sentido, os orientadores apontam o baixo comprometimento dos alunos com os prazos e com a escrita do trabalho final. De fato, a atribuição apontada como de maior dificuldade por parte dos orientadores foi "cumprir e cobrar do aluno o cumprimento dos prazos estipulados”.

No que se refere à figura do Tutor Coorientador, responsável pela orientação da formatação do trabalho e pelo cumprimento de normas e prazo, visando facilitar o trabalho dos Professores-Orientadores, foi considerado algo difícil. Surge, portanto, a necessidade de revisar os mecanismos de interação Aluno-Orientador-Coorientador. Alguns orientadores questionaram a nomenclatura adotada para esse ator no processo de orientação, o que também precisa ser repensado. Outro aspecto considerado de difícil execução foi "verificar a possibilidade de existência de Plágio”. Entretanto, acredita-se que isso pode ser resolvido investindo na formação de orientadores e coorientadores para o uso de softwares específicos. Apesar dessa questão ter sido trabalhada durante as disciplinas curriculares do curso, o plágio foi identificado por vários orientadores no processo de escrita do trabalho final.

A partir dos relatos dos orientadores sobre o uso do Facebook, identificou-se a pertinência de sua adoção como um sistema de suporte para as trocas no processo de orientação. Pode-se investir nesse sistema tanto como um suporte para construir/manter o vínculo com os alunos, quanto para dar suporte às interações síncronas. Para finalizar cabe lembrar que o curso de Pós-Graduação em Mídias na Educação da UFPel está em fase final de execução de sua primeira oferta, e que os resultados da presente pesquisa servem tanto para corrigir o rumo da atual oferta como para melhorar as próximas edições do curso.

\section{Referências}

ALMEIDA, M. E. B. de. Formação de educadores a distância na pós-graduação: potencialidades para o desenvolvimento da investigação e produção de conhecimento. Educ. Soc., Campinas, v. 33, n. 121, dez. 2012 . Disponível em http://dx.doi.org/10.1590/S0101-73302012000400008. acesso em 21 mar. 2013.

BRASIL. Decreto n. 5.622, de 19 de dezembro de 2005. Regulamenta o art. 80 da Lei $\mathrm{n}^{0}$ 9.394, de 20 de dezembro de 1996, que estabelece as diretrizes e bases da educação nacional. Diário Oficial da União, Brasília, DF, 20 dez. 2005.

BRUNETTA, N. et al. Aspectos do Processo de Construção do trabalho de conclusão de curso na modalidade a distância: perspectivas dos alunos, tutores e professores orientadores. Revista Renote, Porto Alegre, v.10, n. 3 dez. 2012. Disponível em: $<$ http://seer.ufrgs.br/renote/article/view/36380/23474> . acesso em 21 mar. 2013.

SCHNITMAN, I. M. A mediação pedagógica e o sucesso de uma experiência educacional on-line. ETD - Educ. Tem. Dig., Campinas, v.12, n.esp., p.287-314, mar. 2011. Disponível em: < www.fae.unicamp.br/revista/index.php/etd/article/view/2263/pdf 61>. acesso em 21 mar. 2013.

TEATINI, J. C, MEC promete triplicar matrículas em EAD e alcançar 600 mil alunos até 2014: UOL Notícias, São Paulo, 24 abr. 2012 Disponível em:

$<$ http://noticias.bol.uol.com.br/educacao/2012/04/24/mec-promete-triplicar-matriculas-em-eadate-2014-e-alcancar-600-mil-alunos.jhtm>. acesso em 21 mar. 2013. 